\title{
No Association between Two Polymorphisms of the Serotonin Transporter Gene and Combined Type Attention Deficit Hyperactivity Disorder
}

X. Xu, ${ }^{1}$ E. Aysimi, ${ }^{1}$ R. Anney, ${ }^{2}$ K. Brookes, ${ }^{1}$ B. Franke, ${ }^{3,4}$ K. Zhou, ${ }^{1}$ C. Buschgens, ${ }^{3}$ W. Chen, ${ }^{1}$ H. Christiansen, ${ }^{5}$ J. Eisenberg, ${ }^{6}$ I. Gabriëls, ${ }^{7}$ I. Manor, ${ }^{8}$ R. Marco, ${ }^{9}$ U.C. Müller, ${ }^{10}$ A. Mulligan, ${ }^{2}$ N. Rommelse, ${ }^{11} \mathrm{M}$. Thompson, ${ }^{12} \mathrm{H}$. Uebel, ${ }^{13} \mathrm{~T}$. Banaschewski, ${ }^{13,14} \mathrm{~J}$. Buitelaar, ${ }^{3}$ R. Ebstein, ${ }^{6} \mathrm{M}$. Gill, ${ }^{2}$ A. Miranda, ${ }^{15}$ F. Mulas, ${ }^{15}$ R.D. Oades, ${ }^{5}$ H. Roeyers, ${ }^{7}$ A. Rothenberger, ${ }^{13}$ J. Sergeant, ${ }^{11}$ E. Sonuga-Barke, ${ }^{12}$ H.-C. Steinhausen, ${ }^{10}$ E. Taylor, ${ }^{1}$ S.V. Faraone, ${ }^{16}$ and P. Asherson ${ }^{1 *}$

\section{American Journal of Medical Genetics Part B, 147, 1306-1309.}

This is the reformatted manuscript submitted - prior to publication in its final form at DOI 10.1002/ajmg.b.30737

1 MRC Social Genetic Developmental and Psychiatry Centre, Institute of Psychiatry, London, UK

2 Neuropsychiatric Genetics Research group, School of Medicine, Trinity College, Dublin, Ireland

3 Department of Psychiatry, Radboud University, Nijmegen Medical Center, Nijmegen, The Netherlands

4 Department of Human Genetics, Radboud University Nijmegen Medical Center, Nijmegen, The Netherlands

5 University Clinic for Child and Adolescent Psychiatry, Essen, Germany

6 S Herzog Memorial Hospital, Jerusalem, Israel

7 Department of Experimental Clinical Health Psychology, Ghent University, Ghent, Belgium

8 ADHD Clinic, Geha Mental Health Center, Petach Tiqva, Israel

9 Department of Developmental and Educational Psychology, University of Valencia, Valencia, Spain

10 Department of Child and Adolescent Psychiatry, University of Zurich, Zurich, Switzerland

11 Department of Clinical Neuropsychology, VU University, Amsterdam, The Netherlands

12 School of Psychology, University of Southampton, Highfield, Southampton, UK

13 Child and Adolescent Psychiatry, University of Göttingen, Göttingen, Germany

14 Central Institute of Mental Health, Department of Child and Adolescent Psychiatry and Psychotherapy, Mannheim, Germany

15 Neurology Unit, Hospital General Laféde Valencia, Valencia, Spain

16 Departments of Psychiatry and Neuroscience and Physiology, SUNY Upstate Medical University, Syracuse, New York, USA

* Corresponding author: p.asherson@iop.kcl.c.uk

\begin{abstract}
:
Several independent studies have reported association between serotonin transporter gene (SLC6A4) polymorphisms and attention deficit hyperactivity disorder (ADHD). Five studies found evidence for association between the long allele of a 44-bp insertion/deletion polymorphism (5-HTTLPR) and ADHD. Another two studies corroborated this finding while a further 6 studies did not find such an association. For a second polymorphism within the gene, a variable number tandem repeat (VNTR) within intron 2, one study demonstrated that the 12/12 genotype was significantly less frequent in ADHD cases compared to controls, while a second study found that the 12-allele was preferentially transmitted to offspring affected with ADHD. To provide further clarification of the reported associations, we investigated the association of these two markers with ADHD in a sample of 1,020 families with 1,166 combined type ADHD cases for the International Multi-Center ADHD Genetics project, using the Transmission Disequilibrium Test. Given the large body of work supporting the association of the promoter polymorphism and mood disorders, we further analyzed the group of subjects with ADHD plus mood disorder separately. No association was found between either of the two markers and ADHD in our large multisite study or with depression within the sample of ADHD cases.
\end{abstract}

Key Words: attention deficit hyperactivity disorder; serotonin transporter gene; SLC6A4; association study. Grant sponsor: NIH; Grant number: R01MH62873 
The human serotonin transporter gene (SLC6A4, formerly known as 5-HTT) is located at chromosome 17q11.2-12. Two common polymorphisms within the gene have been described: a 44-bp insertion/deletion in the promoter region (5-HTTLPR) [Heils et al., 1996] and a variable number tandem repeat in intron 2 (STin2-VNTR) [Lesch et al., 1994]. Several research groups have studied the association between these SLC6A4 polymorphisms and attention deficit hyperactivity disorder (ADHD). Five studies found evidence for association between the long-allele of the 5-HTTLPR polymorphism and ADHD or closely related phenotypes [Seeger et al., 2001; Kent et al., 2002; Retz et al., 2002; Beitchman et al., 2003; Curran et al., 2005]. In accord with these data two other studies found that short/short genotype was significantly underrepresented in children with ADHD compared to controls [Manor et al., 2001; Zoroglu et al., 2002]. However, Li et al. [2007] reported a preferential transmission of the shortallele to ADHD offspring in a Chinese sample and 6 further studies did not find any association between the polymorphism and ADHD [Langley et al., 2003; Kim et al., 2005; Xu et al., 2005; Banerjee et al., 2006; Heiser et al., 2006; Wigg et al., 2006]. A study that combined the available data by pooling odds ratios across studies found a small but significant association of the long allele of 5-HTTLPR with ADHD [Faraone et al., 2005].

For the STin2-VNTR marker one study found that the 12/12 genotype was significantly less frequent in ADHD cases compared to controls [Zoroglu et al., 2002], while another study found that the 12-repeat allele was preferentially overtransmitted to ADHD offspring [Banerjee et al., 2006]. A further 7 studies did not demonstrate an association between STin2-VNTR and ADHD [Kent et al., 2002; Langley et al., 2003; Curran et al., 2005;
Kim et al., 2005; Xu et al., 2005; Heiser et al., 2006; Li et al., 2007].

The aim of this study was to further investigate the relationship between these two polymorphisms of SLC6A4 (in particular the association with 5-HTTLPR that was found to be associated with ADHD following meta-analysis) using a large sample of combined type ADHD cases collected by the International MultiCenter ADHD Genetics (IMAGE) project. In addition because there is strong evidence that short allele of 5-HTTLPR is associated with symptoms of depression, probably by modifying environmental risks [Furlong et al., 1998; Canli and Lesch, 2007], we further investigated whether the short allele was over-transmitted to the group of children with ADHD comorbid with significant mood symptoms. The hypothesis tested being that aspects of ADHD would act as an environmental stressor, increasing the chances of developing depressive symptoms in the presence of the short allele of 5-HTTLPR.

European Caucasian subjects were recruited from 11 specialist clinics in 8 countries: Belgium, Germany, Holland, Ireland, Israel, Spain, Switzerland, and United Kingdom. Ethical approval for this study was obtained from National Institute of Health registered ethical review boards for each center. Detailed information sheets were provided and informed consent obtained from children and their parents. All ADHD probands and their siblings were aged 5-17 at the time of entry into the study and access was required to one or both biological parents for DNA collection. Entry criteria for probands were a clinical diagnosis of DSMIV combined subtype ADHD, having one or more full siblings available for ascertainment of clinical information and DNA collection. Exclusion criteria applying to both probands and siblings include autism, epilepsy, $1 \mathrm{Q}<70$, brain disorders 
and any genetic or medical disorder associated with externalizing behaviors that might mimic ADHD.

All raw data were centralized and stored on a secure database at the MRC Social Genetic Developmental Psychiatry research center in London. The diagnosis of ADHD was made following a parent interview with the Parental Account of Child Symptoms interview [PACS; Taylor et al., 1986] that asks about ADHD symptoms in various settings. An algorithm was used to derive each of the DSM-IV ADHD symptoms from the PACS interview data and these were combined with items that scored two or more from teacher ratings of DSM-IV items taken from the long version of the Conners' Teacher Rating Scale [Conners, 1995]. The diagnosis of ADHD was made if sufficient items were identified to fulfill DSM-IV criteria, and both impairment (based on severity of symptoms identified in the PACS interview) and pervasiveness (based on the presence of ADHD symptoms in more than one setting from PACS and scoring more than one item on the teacher Conners) were present. In a few cases where no Conners data were present pervasiveness was defined on the basis of PACS data alone.

The PACS interview was also used to identify the group of ADHD cases with a possible mood disorder. Although PACS does not formally generate DSM-IV diagnostic categories for mood disorders, it identifies individuals reporting high and impairing levels of mood symptoms. The key criteria for depression were the presence of marked misery lasting more than $6 \mathrm{hr}$ during which time the child could only be cheered up with difficulty, on 3-6 days a week, or the presence of severe misery (could not be cheered up at all), on at least 1 or 2 days a week. Similar frequency criteria applied for other changes in mood that were either marked (showing diminished interest or pleasure in activities, or marked lack of energy and fatigue, lasting $6 \mathrm{hr}$ or more) or severe (no engagement even in normally pleasurable activities).

The final dataset used in this study consisted of 1,020 ADHD families with 1,166 DSM-IV combined type probands. Of these there were 199 ADHD cases (15\% of the cases) with evidence of a comorbid mood disorder from the PACS interview data. DNA was available for both parents in 891 families (87\%) and from one parent in 129 families (13\%). Eighty-eight percent of the ADHD cases were male.

Genotyping followed routine procedures. The 44-bp insertion/deletion 5-HTTLPR polymorphism and the 17-bp STin2-VNTR polymorphism were genotyped using the methods described in Zoroglu et al. [2002]. The program suite UNPHASED was used to test the linkage disequilibrium (LD) between the individual marker locus and haplotypes [Dudbridge, 2003]. TDTPHASE was used for the transmission disequilibrium test (TDT) analysis from family genotype data. In total we obtained data from 1,166 affected children for the two polymorphisms located in the SLC6A4 gene. We found no evidence for the preferential transmission of the long-allele of 5-HTTLPR to affected offspring as previously reported, and also no evidence of biased transmission of the short-allele (Table I). For STin2-VNTR, three alleles (9repeat, 10-repeat, and 12-repeat) were detected in our sample with the most common alleles being the 10-repeat and 12-repeat alleles. The common alleles were not significantly associated with ADHD in this sample (Table 1 ).

We also found no evidence of overtransmission of the 5- HTTLPR risk allele for depression, in the sub-group with ADHD plus evidence of a mood disorder $\left(\chi^{2}=1.9, P=0.17\right.$ for 5 - HTTLPR; $\left.\chi^{2}=2.4\right)$. 
TABLE 1: Results of the TDT Analysis of 5-HTTLPR and STin2-VNTR Polymorphisms

\begin{tabular}{ccccccc}
\hline Polymorphism & Allele & Transmitted & Non-transmitted & $\chi^{2}$ & $P$-value & OR \\
\hline 5-HTTLPR & L & 496 & 462 & 1.21 & 0.27 & 1.07 \\
& $\mathrm{~S}$ & 462 & 496 & 1.21 & 0.27 & 0.93 \\
STin2-VNTR & 9 & 25 & 25 & 0 & 1 & 1.00 \\
& 10 & 462 & 452 & 0.11 & 0.74 & 1.02 \\
& 12 & 463 & 473 & 0.11 & 0.74 & 0.98 \\
\hline
\end{tabular}

5-HTTLPR likelihood ratio test: null $=-664.0$, alternative $=-663.4, \mathrm{LRS}=1.207, \mathrm{df}=1, P=0.272$;

STin2-VNTR likelihood ratio test: null $=-658.5$, alternative $=-658.4, \mathrm{LRS}=0.110, \mathrm{df}=2, P=0.947$.

The degrees of freedom for the allele-specific tests is 1

TABLE 2: Results of the TDT analysis of the haplotypes for 5-HTTLPR and STin2-VNTR Polymorphisms

\begin{tabular}{ccccccc}
\hline Haplotype & Transmitted & freq-T & Non-transmitted & freq-NT & $\chi^{2}$ & $P$-value \\
\hline L-9 & 22 & 0.02 & 21 & 0.02 & 0.02 & 0.88 \\
L-10 & 290 & 0.30 & 269 & 0.28 & 0.62 & 0.43 \\
L-12 & 262 & 0.28 & 262 & 0.28 & 0.00 & 1.00 \\
S-9 & 1 & 0.00 & 0 & 0.00 & 0.00 & 1.00 \\
S-10 & 95 & 0.10 & 95 & 0.10 & 0.00 & 1.00 \\
S-12 & 281 & 0.30 & 304 & 0.32 & 0.68 & 0.41 \\
\hline
\end{tabular}

$\mathrm{T}=$ transmitted NT $=$ non-transmitted.

Global likelihood ratio test: null $=-533.03$, alternative $=-531.93 \mathrm{LRS}=2.200, \mathrm{df}=5, P=0.821$.

Similarly there was no evidence of association with the intron 2 markers in this group ( $P=0.30$ for STin2-VNTR), nor in the group with ADHD with no evidence of a comorbid mood problem with either marker $\left(\chi^{2}=0.74, P=0.39\right.$ for 5-HTTLPR; $\chi^{2}=0.05, P=0.97$ for STin2-VNTR). LD between the two polymorphisms was significant but moderate using the $\mathrm{D}^{\prime}$ and $r^{2}$ statistic $\left(D^{\prime}=0.42, r^{2}=0.29\right)$. There was no evidence of biased transmission of any of the haplotypes (Table 2).

In summary, we investigated the relationship between $A D H D$ and two SLC6A4 polymorphisms that had previously been reported to be associated with ADHD. Our large multisite study of 1,166 combined type probands found no evidence for an association with either of the two polymorphisms. Given the large body of work supporting the association of the promoter polymorphism and mood disorders [Canli and Lesch, 2007] we analyzed the group of subjects with ADHD plus mood disorder separately, but also found no evidence for association. Formal meta-analysis of these with other available datasets is now required to clarify whether the serotonin transporter gene has an etiological role in ADHD susceptibility.

\section{Acknowledgments:}

The IMAGE project is a multi-site, international effort supported by NIH grant R01MH62873 to S.V. Faraone. Site Principal Investigators are Philip Asherson, Tobias Banaschewski, Jan Buitelaar, Richard P. Ebstein, Stephen V. Faraone, Michael Gill, Ana Miranda, Fernando Mulas, Robert D. Oades, Herbert Roeyers, Aribert Rothenberger, Joseph Sergeant, Edmund Sonuga-Barke, and HansChristoph Steinhausen. Senior coinvestigators are Margaret Thompson, Pak Sham, Peter McGuffin, Robert Plomin, Ian Craig and Eric Taylor. Chief Investigators at each site are Rafaela Marco, Nanda Rommelse, Wai Chen, Henrik Uebel, Hanna Christiansen, U. Mueller, Cathelijne 
Buschgens, Barbara Franke, and Lamprini Psychogiou. We thank all the families who kindly participated in this research.

\section{References:}

Banerjee E, Sinha $S$, Chatterjee A, Gangopadhyay PK, Singh $M$, Nandagopal K. 2006. A family-based study of Indian subjects from Kolkata reveals allelic association of the serotonin transporter intron-2 (STin2) polymorphism and attention-deficithyperactivity disorder (ADHD). Am J Med Genet Part B 141B: 361-366.

Beitchman JH, Davidge KM, Kennedy JL, Atkinson L, Lee V, Shapiro S, Douglas L. 2003. The serotonin transporter gene in aggressive children with and without ADHD and non-aggressive matched controls. Ann NY Acad Sci 1008:248251.

Canli T, Lesch K-P. 2007. Long story short: The serotonin transporter in emotion regulation and social cognition. Nat Neurosci 10:1103-1109.

Conners CK. 1995. The Conners Rating Scales: Instruments for assessments of childhood psychopathology. Durham, USA: Duke University.

Curran S, Purcell S, Craig I, Asherson P, Sham P. 2005. The serotonin transporter gene as a QTL for ADHD. Am J Med Genet Part B 134B:42- 47.

Dudbridge F. 2003. Pedigree disequilibrium tests for multilocus haplotypes. Genet Epidemiol 25:115221.

Faraone SV, Perlis RH, Doyle AE, Smoller JW, Goralnick JJ, Holmgren MA, Sklar P. 2005. Molecular genetics of attentiondeficit/ hyperactivity disorder. Biol Psychiatry 57:1313-1323.

Furlong RA, Ho L, Walsh C, Rubinsztein JS, Jain S, Paykel ES, Easton DF, Rubinsztein DC. 1998. Analysis and meta-analysis of two serotonin transporter gene polymorphisms in bipolar and unipolar affective disorders. Am J Med Genet 81:58-63.

Heils A, Teufel A, Petri S, Stober G, Riederer P, Bengel D. 1996. Allelic variation of human serotonin transporter gene expression. J Neurochem 66:2621-2624.

Heiser P, Dempfle A, Friedel S, Konrad K, Hinney A, Kiefl $H$, Walitza $S$, Bettecken $T$, Saar $K$, Linder $M$, Warnke $A$, Herpertz-Dahlmann B, Schäfer $H$, Remschmidt H, Hebebrand J. 2006. Family-based association study of serotonergic candidate genes and attention-deficit/ hyperactivity disorder in a German sample. J Neural Transm 114:513-521.

Kent L, Doerry U, Hardy E, Parmar R, Gingell K, Hawi Z, Kirley A, Lowe N, Fitzgerald M, Gill M, Craddock N. 2002. Evidence that variation at the serotonin transporter gene influences susceptibility to attention deficit hyperactivity disorder (ADHD): Analysis and pooled analysis. Mol Psychiatry 7:908-912.

Kim SJ, Badner J, Cheon KA, Kim BN, Yoo HJ, Kim SJ, Cook E Jr, Leventhal BL, Kim YS. 2005. Family-based association study of the serotonin transporter gene polymorphisms in Korean ADHD trios. Am J Med Genet Part B 139B:14-18.

Langley K, Payton A, Hampshere M, Pay $H M$, Lawson D, Turic D, Ollier W, Worthington J, Owen MJ, O'Donovan MC, Thapar A. 2003. No evidence of association of two 5HT transporter gene polymorphisms and attention deficit hyperactivity disorder. Psychiatric Genet 13:107-110.

Lesch KP, Balling U, Gross J, Strauss K, Wolozin BL, Murphy DL. 1994. Organisation of the human serotonin transporter gene. J Neural Transm 95: 157-162. 
Li J, Wang $Y$, Zhou R, Zhang H, Yang L, Wang B, Faraone SV. 2007. Association between polymorphisms in serotonin transporter gene and attention deficit hyperactivity disorder in Chinese Han subjects. Am J Med Genet Part B 144B:14-19.

Manor I, Eisenberg J, Tyano S, Sever $Y$, Cohen H, Ebstein RP, Kotler M. 2001. Family-based association study of the serotonin transporter promoter region polymorph-ism (5-HTTLPR) in attention deficit hyperactivity disorder. Am J Med Genet 105:91-95.

Retz $\mathrm{W}$, Thome J, Blocher D, Baader $\mathrm{M}$, Rosler M. 2002. Association of attention deficit hyperactivity disorderrelated psychopathology and personality traits with the serotonin transporter promoter region polymorphism. Neurosci Lett 319:133-136.

Seeger G, Schloss P, Schmidt MH. 2001. Functional polymorphism within the promoter of the serotonin transporter gene is associated with severe hyperkinetic disorders. Mol Psychiatry 6:235-238.
Taylor E, et al. 1986. Conduct disorder and hyperactivity: I. Separation of hyperactivity and antisocial conduct in British child psychiatric patients. $\mathrm{Br} J$ Psychiatry 149:760-767.

Wigg KG, Takhar A, Ickowicz A, Tannock R, Kennedy JL, Pathare $T$, Malone $M$, Schachar R, Barr CL. 2006. Gene for the serotonin transporter and ADHD: No association with two functional polymorphisms. Am J Med Genet Part B 141B:566-570.

Xu X, Mill J, Chen CK, BrookesK, Taylor E, Asherson P. 2005.Family-based association study of serotonin transporter gene polymorphisms in attention deficit hyperactivity disorder: No evidence for association in UK and Taiwanese samples. Am J Med Genet Part B 139B:11-13.

Zoroglu SS, Erdal ME, Alasehirli B, Erdal N, Sivasli E, Tutkun $H$, Savas HA, Herken $H$. 2002. Significance of serotonin transporter gene 5-HTTLPR and variable number of tandem repeat polymorphism in attention deficit hyperactivity disorder. Neuropsychobiology 45:176-181. 